\title{
Kaposi sarcoma incidence in the Swiss HIV cohort study before and after highly active antiretroviral therapy S Franceschi ${ }^{* 1}$, L Dal Maso ${ }^{2}$, M Rickenbach ${ }^{3}$, J Polesel ${ }^{2}$, GM Clifford ${ }^{1}$ and the Swiss HIV cohort study
}

Address: ${ }^{1}$ International Agency for Research on Cancer, Lyon, France, ${ }^{2}$ Epidemiology and Biostatistics Unit, Aviano Cancer Center, Aviano, Italy and ${ }^{3}$ Coordination and Data Center, Swiss HIV Cohort Study, Lausanne, Switzerland

* Corresponding author

from I I th International Conference on Malignancies in AIDS and Other Acquired Immunodeficiencies (ICMAOI): Basic, Epidemiologic, and Clinical Research

Bethesda, MD, USA. 6-7 October 2008

Published: 17 June 2009

Infectious Agents and Cancer 2009, 4(Suppl 2):PI7 doi:I0.II86/I750-9378-4-S2-PI7

This abstract is available from: http://www.infectagentscancer.com/content/4/S2/PI7

(c) 2009 Franceschi et al; licensee BioMed Central Ltd.

Between 1984 and 2006, 12,959 people with HIV/AIDS (PWHA) in the Swiss HIV Cohort Study contributed a total of 73,412 person years of follow-up, 35,551 of which derived from PWHA treated with highly active antiretroviral therapy (HAART). Out of 597 incidents of Kaposi sarcoma (KS) identified, 52 were among HAART users.

Cox regression was used to estimate hazard ratios (HR) and corresponding 95 percent confidence intervals (CI). KS incidence fell abruptly from 1996 to 1998 to reach a plateau at 1.4 per 1000 person years afterwards. Men having sex with men (MSM) and birth in Africa or the Middle East were associated with KS in both non-users and users of HAART, but the risk pattern by CD4 cell count differed. Only very low CD 4 cell count ( $<50$ cells/il $)$ at enrolment or at HAART initiation were significantly associated with KS among HAART users. The HR for KS declined steeply in the first months after HAART initiation and continued to be low 7 to 10 years afterwards (HR, 0.06; 95\% CI, 0.02$0.17)$. Out of 52 KS cases among HAART users, 33 out of $52(63.5 \%)$ KS cases among HAART users arose among PWHA who had stopped treatment or used HAART for less than 6 months. 